\title{
Chemists synthesize a single naming system
}

\section{David Adam, London}

An international team of chemists is working on something that chemistry sorely lacks - a consistent and comprehensive way of labelling all chemical compounds.

The new technique will apply computer algorithms to molecular structures, generating a unique digital signature for any chemical compound. The new labels are not intended to replace common chemical names, but to allow easier linking to compounds in online chemical databases and journals.

"The hope is that all organizations that handle information on chemicals will be able to use a single format to say what the chemical is," says Alan McNaught, general manager of the production division at the Royal Society of Chemistry in Cambridge, who coordinates the project for the International Union of Pure and Applied Chemistry (IUPAC).

Right now there is no single international standard for identifying chemicals. The IUPAC and the American Chemical Society use different rules. Some drug companies, as well as different branches of chemistry, have their own chemical-naming systems. Even simple structures can cause confusion. For example, the formal name for acetic acid, the main ingredient in vinegar, is ethanoic acid.

IUPAC believes that its new system which would be freely available to all — could unify the different approaches. Tentatively

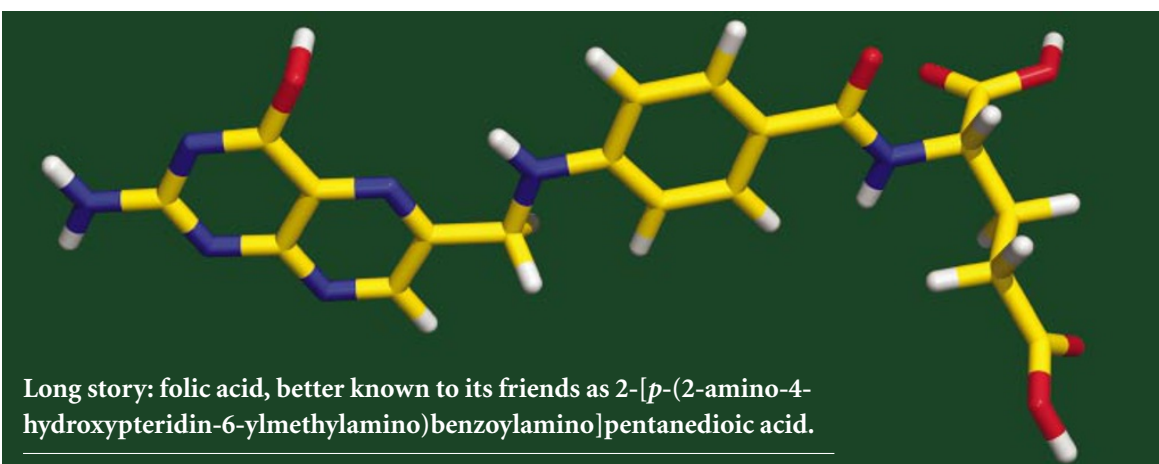

known as IChI, for IUPAC chemical identifier, its development is being led by a team at the US National Institute of Standards and Technology (NIST) in Gaithersburg, Maryland.

A preliminary version of the software covering well-defined, covalently bonded organic molecules was released this year to let other chemists test the idea. It labels each atom in a compound in a way that does not depend on how the structure is drawn, and converts the label to a string of characters. The format has not been finalized, but at present ethane is ' $\mathrm{C} 3 \mathrm{C} 3,2-1$ ', for example, and acetone is 'C3C3OC, 4-1-2-3' (the labels are easily converted to structures using the algorithm). The process is reversible, so molecular structures can be generated from the identifiers.

The next step is to extend the system to include more complex organic compounds, such as polymers, and ultimately to tackle inorganic compounds. By adding it to software packages commonly used to draw chemical structures, the NIST team hopes that IChI will enter into widespread use.

In effect, the IChI number will provide each chemical molecule with a digital object identifier (DOI) - a concept increasingly being applied to everything from scientific papers to individual genes. Jonathan Goodman, a chemist at the University of Cambridge, says chemistry suits this approach well. "Molecules are a wonderful unit of information to treat in this way," he says. "They are complex enough to have lots of interesting features and difficulties but simple enough to represent quite a small subset." www.iupac.org/projects/2000/ 2000-025-1-800.html

\section{NASA's critics demand a few more steps into space}

Tony Reichhardt, Washington

Critics of Sean O'Keefe, the new NASA administrator, are complaining that his nuts-and-bolts management style is leaving the space agency bereft of what ex-president George Bush once called "the vision thing".

The agency's human spaceflight programme is "adrift, with no clear vision or commitment to any goals after the completion of the International Space Station", Congressman Nick Lampson (Democrat, Texas) told the House of Representatives on 15 May.

Lampson was introducing the Space Exploration Act of 2002, which would require NASA to complete a series of specific tasks, starting with building a reusable space vehicle within eight years that is capable of carrying astronauts beyond Earth orbit to locations where large space telescopes could be constructed. Under the act, NASA would also be charged with building, within 10 years, a vehicle capable of reaching nearEarth asteroids. A lunar research facility would follow within 15 years, and a spacecraft for reaching Mars within 20.



The bill takes an approach that is becoming fashionable among long-term space planners: it proposes a series of incremental steps, rather than the grand sweep of a single mission to Mars. It calls for a competitive programme, run by a new Office of Exploration, modelled on NASA's Discovery series of planetary-exploration missions, with an initial budget of $\$ 50$ million next year and \$200 million in 2004

Lampson's proposal contrasts sharply with the approach being taken by the White House and O'Keefe, who has made it clear that he envisages a period of incremental technology development for NASA, rather than identifying any grandiose new goals.

Although Lampson's bill has little chance of passing Congress, NASA's recent 'go-slow' strategy has been criticized by other politicians, including Tom DeLay (Republican, Texas), the majority whip in the House and one of Washington's most powerful figures. During a congressional hearing last month, DeLay branded O'Keefe's plans for human spaceflight "timid and anaemic".

Most of the bill's sponsors are from districts near NASA's Johnson Space Center in Texas, where the US astronaut programme is based. But its arrival, observers say, reflects a growing weight of opinion that, with the space station downsized and no other large projects on the horizon, NASA's 40-year-old human-spaceflight programme is in danger of withering away. 


\section{Think-tank calls for an end to DNA deception}

David Adam, London

Deceitfully obtaining and testing someone else's DNA would become a criminal offence under recommendations delivered to the British government by a high-powered commission.

The Human Genetics Commission says it is worried that no law currently prevents DNA samples of the rich and famous being obtained, analysed and published - or stops unscrupulous family members from taking material from children and secretly carrying out paternity tests.

The recommendation is one of several made in a report, Inside Information, that the commission was due to release on 21 May. The government has welcomed the report and says that it will consider the issues raised during the government's discussions on genetics, the results of which it expects to publish later this year.

"There must be systems in place that promote trust about the way that clinicians, researchers and ultimately the state handle genetic information," it says. "People need to feel confident that their information is safe from being used in the wrong way." To address these concerns, it calls for wider debate over ways to control the use of genetic information in police forensic science, clinical research projects and setting personal insurance premiums.

Civil-liberties groups in Britain are particularly worried by a recent case in which an HIV-positive prisoner volunteered a blood sample for a genetic study, only to see the sample taken by police and used successfully to prosecute the man for deliberately transmitting HIV to an ex-girlfriend.

Some researchers are worried that similar cases will ultimately deter prisoners and others from consenting to participate in medical trials or in projects such as the Medical Research Council's Biobank UK, which hopes to collect DNA samples from half a million people (see Nature 417, 9; 2002). The commission says that a law may be needed to bar police and other officials from access to genetic research databases.

"We've tried to identify the main principles which should govern the way our society deals with personal genetic information," says Alexander McCall Smith, a professor of law at the University of Edinburgh who specializes in medical and criminal law and is vice-chairman of the Human Genetics Commission. Many of the techniques and issues considered are only at very early stages, but it is important to establish a regulatory framework of legislation and guidelines before they develop further, he says.

The commission says that public concern may arise as growing knowledge of genetics



Concerns are growing about covert use of DNA samples (above) for forensic and insurance purposes.

allows aspects of a suspect to be built up from samples found at a crime scene - or even to predict elements of the suspect's behaviour or medical history. McCall Smith points out, for example, that the forensic-science service can already tell the police the chances of a suspect having ginger hair based on the analysis of just one gene, that encoding melanocortin receptor 1 .

Paul Debenham, director of life sciences at the Laboratory of the Government Chemist, based in London, which provides genetic-analysis services for the police and government, says he would welcome guidelines covering the forensic uses of DNA. Experts say, however, that legislation to prevent authorities obtaining medical information from DNA would be difficult to craft in such a way as to allow the collection of data related to suspects' appearances.

\section{Biotech firm's accounts scrutinized}

\section{Erika Check, Washington}

A Massachusetts biotechnology company that usually likes to keep a high profile received some unwanted publicity this week when government auditors raised questions about its financial viability.

Auditors from the health department were asked to trawl through the accounts of Advanced Cell Technology (ACT) of Worcester by Congressman Joe Pitts (Republican, Pennsylvania), who is strongly opposed to human cloning. He says that he wanted to find out whether the company had illegally used federal money

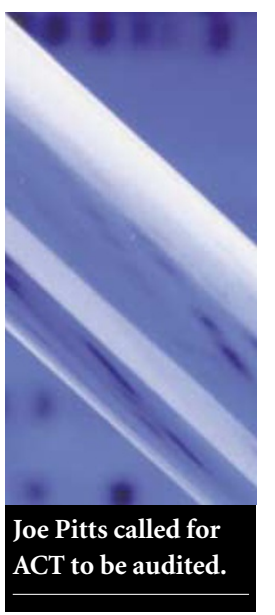
from the National Institutes of Health (NIH) when it created cloned human embryos in November last year (see Nature 414,477 ; 2001)

The auditors say that they found "no evidence that NIH's funds supported ACT's embryocloning activities". But they did find that ACT's accounting system was inadequate, and that the company had made "unallowable" equipment purchases with the grant money.

They also found what the published audit calls "concerns regarding ACT's financial viability". And the audit raises what it terms "concerns regarding the continuity of NIH-funded research" under two NIH grants totalling \$1.8 million, since the grants' principal investigators left the company this spring after one year of service with the company.

ACT says it had done nothing wrong, but has agreed to return the funds in question to the government, in line with the auditor's recommendations.

Michael West, president of ACT, accuses Pitts of making misleading statements about his company on the basis of the audit. "After weeks of looking at every scrap of paper in the company, they found no evidence that we misappropriated grant funds for human embryo research," he says. "So they tried to make it look like we were misappropriating grant money in other ways - and it's not true."

ACT is in no worse shape financially than many other similar companies, West says. "We're clearly a small, struggling biotechnology company," he says, "but we're doing better than most." 